\title{
Determinants and spatial distribution of institutional delivery in Ethiopia: evidence from Ethiopian Mini Demographic and Health Surveys 2019
}

\author{
Girma Gilano $^{1^{*} \mathbb{D}}$, Samuel Hailegebreal ${ }^{1}$ and Biniyam Tariku Seboka ${ }^{2}$
}

\begin{abstract}
Background: Over the past few decades, maternal and child mortality had drawn the attention of governments and policymakers. Institutional delivery has been among the implementations needed to reduce maternal and child mortality. The fact that the problem was persisted intensified studies to research for more factors. Thus, the current study was intended for further analyses of EMDHS to identify the magnitude, spatial patterns, and predictors of institutional delivery.
\end{abstract}

Methods: A cross-sectional survey data from EMDHS 2019 was analyzed involving 5488 reproductive-age women regarding institutional deliveries. We presented descriptive statistics using mean, standard deviations, and proportions. To check the nature of the distribution of institutional delivery, we applied the global Moran's I statistics. GetisOrd Gi statistics was applied to detect spatial locations, and we applied spatial interpolation to predict unknown locations of institutional delivery using the Ordinary Kriging method. Kulldorff's SatScan was also applied to identify the specific local clustering nature of institutional delivery using the Bernoulli method. We applied multilevel binary logistic regression for the scrutiny of individual and community-level factors. We applied $P<0.25$ to include variables in the model and $P<0.05$ to declare associations. AOR with $95 \% \mathrm{Cl}$ was used to describe variables.

Results: The prevalence of institution/facility delivery was $2666.45(48.58 \%)$ in the survey. The average number of children was $4.03 \pm 2.47$, and most women in this survey were in the age range of the 25 -29years (31.84\%) and 30-34years (21.61\%). Women who learned primary education ( $\mathrm{AOR}=1.52 ; 95 \% \mathrm{Cl} 1.20-1.95)$, secondary education $(A O R=1.77 ; 95 \% \mathrm{Cl} 1.03-3.07)$, and higher education ( $\mathrm{AOR}=5.41 ; 95 \% 1.91-15.25)$, while those who can read and write sentences ( $A O R=1.94 ; 95 \%$ 1.28-2.94), Rich ( $A O R=2.4095 \% \mathrm{Cl} 1.82-3.16)$, and those followed 1-2 ANC $(\mathrm{AOR}=2.08 ; 95 \% \mathrm{Cl} 1.57-2.76), 3 \mathrm{ANCs}(\mathrm{AOR}=3.24 ; 95 \% \mathrm{Cl} 2.51-418)$, and $\geq 4$ ANCs ( $\mathrm{AOR}=4.91 ; 95 \% \mathrm{Cl} 3.93-6.15)$ had higher odds of delivering at health institutions.

Conclusion: The institutional delivery was unsatisfactory in Ethiopia, and there were various factors associated differently across the different regions. Pastoralist regions showed high home delivery than institutions which invites further interventions specific to those regions. Factors like age, highest education level achieved, preceding birth

\footnotetext{
*Correspondence: gilanog@yahoo.com

1 Department of Health Informatics, School of Public Health, College

of Medicine and Health Sciences, Arba Minch University, Arba Minch, Ethiopia

Full list of author information is available at the end of the article
} permits use, sharing, adaptation, distribution and reproduction in any medium or format, as long as you give appropriate credit to the original author(s) and the source, provide a link to the Creative Commons licence, and indicate if changes were made. The images or other third party material in this article are included in the article's Creative Commons licence, unless indicated otherwise in a credit line to the material. If material is not included in the article's Creative Commons licence and your intended use is not permitted by statutory regulation or exceeds the permitted use, you will need to obtain permission directly from the copyright holder. To view a copy of this licence, visit http://creativecommons.org/licenses/by/4.0/. The Creative Commons Public Domain Dedication waiver (http://creativeco mmons.org/publicdomain/zero/1.0/) applies to the data made available in this article, unless otherwise stated in a credit line to the data. 
interval, literacy status, wealth status, birth order, regions, and rural residences were all affected institutional delivery so that interventions considering awareness, access, and availability of the services are vital.

Keywords: Institutional delivery, Spatial distribution, Ethiopia, EMDHS data

\section{Plain English summary}

Maternal and child mortality had drawn the attention of governments and policymakers internationally since 1990s. A lot has been said and tried to reduce maternal and child mortality rates by the government of Ethiopia. Initially, toward the end of MDGs period, the country has been successful in achieving some of the goals related to child and maternal mortality. However, after scene of many implementations, now everything looks downcast again. This fact sparked the need to re-assess the status of the country and provide information for further policy decisions. Currently, we were aimed at providing country representative information from EMDHS data regarding the magnitude, spatial pattern, and predictors of in institutional delivery.

Factors like age, highest education level achieved, preceding birth interval, literacy status, wealth status, birth order, regions, and rural residences were all affected institutional delivery. However, since home delivery was higher and more worsen in pastoralist regions in the country, it should draw more attentions to make interventions considering awareness, access, and availability of the services in vital areas.

\section{Background}

The safety of the mother and newborn is always the target during delivery and can be improved by institutional delivery. Developing countries have many constraints in reducing maternal and newborn problems due to access, availability, and awareness [1]. As a country in the SubSaharan region, Ethiopia got similar limitations regarding maternal and child cares. Henceforth, the country planned to increase institutional delivery from $20 \%$ in 2011 to $60 \%$ in 2015 [2]. Because of the various factors, the country wasn't able to achieve as planned. Many studies indicated that there was a high proportion of home delivery in the country [3-9]. There were various factors cited affecting women to prefer home over institutions for delivery. A study conducted in the Farta district indicated that the magnitude of institutional delivery was $64.4 \%$. Family size, accessibility of transportation, planned pregnancy, information about the place of delivery, participation of women in monthly health conference (PWMHC), information about exempted service, and having antenatal care (ANC) follow up during their last pregnancy were predictors $[10,11]$. In other studies, institutional delivery was $38.9 \%$ and influenced by focused antenatal care, multiple gestations, urban residence, and formal education of the women $[12,13]$.

Residence, region, maternal education, wealth status, ANC visit, preceding birth interval, and community media exposure were all predictors of the institutional delivery from other studies [14-16]. Institutional delivery was $18.2 \%$ in Oromia regional state, where urban residence, maternal education, pregnancy-related health problems, previous history of prolonged labor, and the decision made by the husbands or relatives put forth a positive correlation [17]. There was high variation throughout different administrative levels in the country. For instance, institutional delivery was $72 \%$ in Bule Hora in Oromiya [18]; 89.1\% in Damot district in SNNP [19]; 61.5\% in North-Western part of the country [20]; 76\% in Southwest Ethiopia [21]; 71.7\% in Dejen Woreda; $78.8 \%$ in Bahir Dar [22]; 18.3\% in Dangila woreda; $47 \%$ in semi-urban parts of the country [23]; 38\% in Mandura district [24]; 53\% in Hossana town [25]; 74\% in Dallocha town [26] and $49 \%$ in Hetosa district [27]. The rate of increase was 5.4\% in 2000 and 11.8\%,2011 [28]. Ethiopia showed a good achievement toward the millennium development goal five [29], although the contextual facts look unchanged significantly. The plan to upsurge institutional delivery from $20 \%$ in 2011 to $60 \%$ in 2015 was not adequately achieved until recently from the above literature. In the countries like Ethiopia where resources are very limited, there were limited chances to collect country representative data; however, analyzing the data from EMDHS-2019 enabled us to provide the countrylevel figures. And it is paramount to identify modified and persistent factors for unsuccessful for the next health plans. Therefore, our study was aimed at identifying the prevalence and factors through spatial, descriptive, and multilevel analyses to support further policies.

\section{Methods}

\section{Data source and participants}

Ethiopia is the country located at $\left(3^{\circ}-14^{\circ} \mathrm{N}, 33^{\circ}-48^{\circ} \mathrm{E}\right)$. The country had undertaken four standard Demographic Health Surveys (EDHS). The country started EDHS in the year 2000 and conducted every five years since then. There were also two Ethiopian Mini Demographic 
Health Surveys (EMDHS) conducted in 2014 and 2019. EMDHS usually conduct between the standard EDHS (two to three years) after the EDHS conducted. The 2019 EMDHS is the second nationwide mini survey conducted in the country. In Ethiopian DHS, data has been collected using a two-level multistage stratified cluster sampling to pick eligible respondents from rural and urban areas. For the current analysis, we used Ethiopia Mini Demographic Health Survey (EMDHS) 2019 data. All nine regions and two city administrations were involved in the data collection. The regions were further categorized as agrarian (Benishangul-Gumuz Amhara, Southern Nations, Nationalities, and People Gambela, Oromia, Harari, Region (SNNPR), and Tigray), pastoralists (Afar and Somali), and city administrations (Addis Ababa and DireDawa) contextually. We retrieved the data from the DHS website: (www.dhsprogram.com) after the measure program allowed us to download the datasets. The weighted sample became 5488 women who had live births in the last five years before the survey. They conducted the interview on the permanent residents and visitors who stayed the day before the survey in the residences, and it was a face-to-face manner [30].

\section{Study variables}

The outcome variable for this study was the health institutions/facilities delivery, which was coded as " 0 " if the women gave birth at home and "1" if the women gave birth at a health facility. Institutions/facilities delivery was stated as the births at health institution/facility within five years afore the survey.

\section{Individual-level (covariates) variable}

Maternal education, maternal age, religion, ANC followup, sex of household head, literacy, the total number of children, birth order, preceding birth interval, the timing of 1st ANC visit, wealth index, and marital status were the variables.

\section{Community-level variable}

Region and place of residence.

\section{Statistical analysis \\ Descriptive statistics}

Before conducting the descriptive data analysis, we weighted the data to adjust the non-proportional allocation of samples to strata and regions. Then, descriptive statistics were presented using weighted and unweighted frequencies, mean \pm (standard deviations), and percentage, while all analyses were performed using STATA version 15 (STATA Corporation. IC., TX, USA). The mean-variance inflation factor also was checked to be 3.53 , which was in the acceptable range.

\section{Spatial analysis}

For spatial analysis, we used ArcGIS 10.7 that determined the clustering, dispersion, and random distribution nature of the institutional delivery. Moran's I output lies between $(-1$ to +1$)$. The values close to -1 indicated dispersed institutional delivery, and those closes to +1 indicated clustering distribution. After discovering significant global autocorrelation, we tested the local Getis Ord statistics to identify the areas with high and low institutional deliveries [31].

\section{Spatial interpolation}

For statistical optimization of the weight, the Ordinary Kriging spatial interpolation method was applied, and enabled us to make the prediction of institutional delivery for un-sampled areas of the country.

\section{SaTscan analysis}

SaTScan Version 9.6 software was used for the local cluster detection. A circular window that moves systematically throughout the study area was used to identify a significant clustering of institutional delivery. We presented the results of primary and secondary observed clusters using log-likelihood (LL) and $p$-value $<0.05$.

\section{Multilevel binary logistic regression}

Since the data from country representative surveys are usually clustered or have hierarchical structure, we applied multilevel analysis. We went through four consecutive models building strategies to identify felicitous predictors of institutional delivery in the country. Model 0 is an empty/null (the intercept only model) existed before addition of the predictors. Model 1 (fixed effect model) included all individual-level variables that were initially significant at $p$-value of $<0.25$ to determine the level of variance explained by the model. Model 2 (random effect model) included cluster-level (community -level) variables and model 3 (the mixed effect model) was the final model in which both the individual and community level variables introduced to judge final model performance. The log of the probability of the institutional delivery was modeled using multilevel binary logistic regression as:

$\log \left(\frac{\pi_{\mathrm{ij}}}{1-\pi_{\mathrm{ij}}}\right)=\beta_{0}+\beta_{0} \mathrm{X}_{\mathrm{ij}}+\beta_{2} \mathrm{Z}_{\mathrm{ij}}+u i j$; where, $\mathrm{i}$ and $\mathrm{j}$ are the level 1 (individual) and level 2 (community) units; $\mathrm{X}$ and $\mathrm{Z}$ refer to individual and community-level variables, in sequence. Mij is the probability of the institutional delivery for the $\mathrm{i}^{\text {th }}$ mother in the $\mathrm{j}^{\text {th }}$ community. We resolute random effect using Intra-community Correlation (ICC), ICC $=\frac{\sigma_{a}^{2}}{\sigma^{2} a+\sigma^{2} b}$; where, $\sigma_{a}^{2}$ is the community level variance and $\sigma_{b}^{2}$ indicates individual level variance. The variance $\left(\sigma_{b}^{2}\right)$ is equal to $\pi^{2} / 3$ which is the fixed value. Likelihood Ratio (LR) test for model comparison and 
deviance (-2LL) for the goodness of fit check were calculated, while Median Odds Ratio (MOR) and Proportional Change in Variance (PCV) were also estimated [32].

Finally, the mixed effect model, which included both fixed and random effect variables were fitted. To include variable in the model $p$-value $<0.25$ and to declare association $p$-value $<0.05$ were used.

AOR with 95\% CI was also used to articulate the results.

\section{Results}

Descriptive statistics

Institutional delivery

We analyzed the data on 5488 weighted reproductive-age women who gave birth in the last five years earlier to the survey and found 2666.45(48.58\%) of them delivered at health institution/facility.

Individual-level characteristics The average number of children in families in the survey was $4.03 \pm 2.47$, and the average preceding birth interval was $40.61 \pm 26.30$ months. Most women in this survey were in the age group of the $25-29$ years $(31.84 \%$ ) and $30-34$ years (21.61\%). In other words, 53.55 and $35.47 \%$ were learned no education and primary education, respectively. Similarly, $47.45 \%$ of the women had no ANC follow-ups, while $30.52 \%$ of women were followed ANC of $\geq 4$ visits. Economically, $45.53 \%$ of the women were poor, while $35.57 \%$ were in the rich category. Nearly two-thirds of the women cannot read and write (64.34\%), and those who can read or write the complete sentence were $20.83 \%$.

Community-level characteristics The higher portions of the women were from Oromia (40.17\%), SNNP (19.94\%), and Amhara (18.82\%) regions. Three-fourth $(75.20 \%)$ of the women were from rural-based places of residences (Table 1).

\section{Spatial analysis Moran analysis}

Examining spatial autocorrelation, we recognized that the distribution of institutional delivery was non-random in Ethiopia. We also learned that the global Moran's I test was $0.66(p<0.0001)$. As global Moran's I is significant and greater than zero, we concluded that the distribution was clustered. By this, the null hypothesis which stated random distribution of institutional delivery was rejected at Moran's I test of $0.66(p<0.001)$ (Fig. 1$)$.

\section{Spatial distribution of institutional delivery}

The geo-distribution of institutional delivery was clustered in some parts of the country. Based on the
Table 1 Socio-demographic characteristics of women aged 14-49year in Ethiopia, EMDHS 2019

\begin{tabular}{|c|c|c|}
\hline Variables & $\begin{array}{l}\text { Unweighted } \\
\text { frequency } \\
(\%)\end{array}$ & Weighted frequency (\%) \\
\hline \multicolumn{3}{|l|}{ Age in 5 yrs group } \\
\hline $15-19$ & $295(5.17)$ & $263.25(4.80)$ \\
\hline $20-24$ & $1131(19.82)$ & $1017.74(18.54)$ \\
\hline $25-29$ & $1847(32.37)$ & $1747.6(31.84)$ \\
\hline $30-34$ & $1227(21.50)$ & $1185.75(21.61)$ \\
\hline $35-39$ & $757(13.27)$ & $797.16(14.56)$ \\
\hline $40-44$ & $112(1.96)$ & $368.35(6.69)$ \\
\hline $45-49$ & & $107.38(1.96)$ \\
\hline \multicolumn{3}{|l|}{ Region } \\
\hline Tigray & $453(7.94)$ & $370.60(6.75)$ \\
\hline Afar & $650(11.39)$ & $85.56(1.56)$ \\
\hline Amhara & $503(8.82)$ & $1032(18.82)$ \\
\hline Oromia & $717(12.57)$ & $2204.46(40.17))$ \\
\hline Somali & $636(11.15)$ & $408.10(7.44)$ \\
\hline Benishangul & $526(9.22)$ & $66.89(1.22)$ \\
\hline SNNPR & $651(11.41)$ & $1105.91(19.94)$ \\
\hline Gambela & $436(7.64)$ & $23.85(0.43)$ \\
\hline Harari & $445(7.80)$ & $16.28(0.30)$ \\
\hline Addis Ababa & $290(5.08)$ & $155.73(2.84)$ \\
\hline Dire Dawa & $399(6.99)$ & $29.56(0.54)$ \\
\hline \multicolumn{3}{|c|}{ Highest educational level } \\
\hline No education & $3125(54.77)$ & $2938.85(53.55)$ \\
\hline Primary & $1810(31.72)$ & $1946.96(35.47)$ \\
\hline Secondary \& Higher & $473(8.29)$ & $408.61(7.45)$ \\
\hline Above higher & $298(5.22)$ & $193.88(3.53)$ \\
\hline \multicolumn{3}{|l|}{ Religion } \\
\hline Orthodox & $1601(28.06)$ & $1840.91(33.54)$ \\
\hline Protestant & $1048(18.37)$ & $1452.63(26.47)$ \\
\hline Muslim & $2963(51.93)$ & $2098.60(38.24)$ \\
\hline Others & $94(1.65)$ & $96.15(1.75)$ \\
\hline \multicolumn{3}{|l|}{ Marital status } \\
\hline Single & $30(0.53)$ & $22.44(0.41)$ \\
\hline Married & $5438(95.30)$ & $5254.60(95.74)$ \\
\hline Divorced & $59(1.03)$ & $65.58(1.20)$ \\
\hline Divorced & $179(3.14)$ & $145.67(2.65)$ \\
\hline \multicolumn{3}{|l|}{ ANC visits } \\
\hline No visit & $2820(49.42)$ & $2604.44(47.45)$ \\
\hline $1-2$ visit & $482(8.45)$ & $418.20(7.62)$ \\
\hline 3 visit & $756(13.25)$ & $790.43(14.40)$ \\
\hline$\geq 4$ visits & $1648(28.88)$ & $11,675.23(30.52)$ \\
\hline \multicolumn{3}{|l|}{ Place of residence } \\
\hline urban & $1320(23.13)$ & $1361.00(24.80)$ \\
\hline rural & $4386(76.87)$ & $4127.31(75.20)$ \\
\hline \multicolumn{3}{|l|}{ Place of delivery } \\
\hline Home & $2859(50.1)$ & $2821.85(51.42)$ \\
\hline Health facility & $2847(49.89)$ & 2666.45 (48.58) \\
\hline
\end{tabular}


Table 1 (continued)

\begin{tabular}{|c|c|c|}
\hline Variables & $\begin{array}{l}\text { Unweighted } \\
\text { frequency } \\
(\%)\end{array}$ & Weighted frequency (\%) \\
\hline \multicolumn{3}{|l|}{ Timing of ANC visit } \\
\hline$<3$ mths & $108(3.72)$ & $85.22(2.95)$ \\
\hline $3-6 m$ ths & $2241(77.28)$ & $2302.83(79.67)$ \\
\hline 7mths & $3397(59.53)$ & $502.36(17.38)$ \\
\hline \multicolumn{3}{|l|}{ Literacy } \\
\hline $\begin{array}{l}\text { Can't read at all sentence } \\
\text { Read and write sentence }\end{array}$ & $\begin{array}{l}3632(63.65) \\
568(9.95)\end{array}$ & $\begin{array}{l}3531.04(64.34) \\
661.36(12.05)\end{array}$ \\
\hline Read whole sentence & $1116(19.56)$ & $1143.20(20.83)$ \\
\hline $\begin{array}{l}\text { No card with required } \\
\text { language. }\end{array}$ & $390(6.83)$ & $152.71(2.78)$ \\
\hline \multicolumn{3}{|l|}{ Wealth status } \\
\hline Poor & $2932(51.38)$ & $2489.70(45.53)$ \\
\hline Middle & $796(13.95)$ & $1037.39(18.90)$ \\
\hline Rich & $1978(34.67)$ & $1952.21(35.57)$ \\
\hline \multicolumn{3}{|l|}{ Birth order } \\
\hline First & $1254(21.98)$ & $1196.83(21.81)$ \\
\hline 2nd & $1055(18.48)$ & $985.10(17.95)$ \\
\hline$>3$ & $3397(59.53)$ & $3306.38(60.24)$ \\
\hline \multicolumn{3}{|l|}{ Sex of the household head } \\
\hline Male & $4560(79.92)$ & $4738.41(86.34)$ \\
\hline Female & $1146(20.08)$ & $749.89(13.66)$ \\
\hline
\end{tabular}

NB: SNNP South Nation Nationalities people, ANC Antenatal care

Gettis-OrdGi statistical analysis, Addis Ababa city, Dire Dawa city, Hawassa town in SNNP, some places in Benishangul Gumuz, and few places in the Oromia region displayed the highest prevalence of institutional delivery showing a significant Z-score with $90 \%$ and above confidence levels (Fig. 2).

\section{Ordinary kriging interpolation}

To determine the occurrence of institutional delivery throughout the un-sampled areas, Ordinary Kriging interpolation measured the distance from the known point to predict unknown points/areas and indicated the point in the ranges of the event occurrences. The evidence from Fig. 3 showed that the possible areas for the event happening were Addis Ababa, Dire Dawa, Benishangule, Tigray, and some parts of Gambella.

\section{SaTscan statistics}

In all spatial analyses above, we tried to identify the nature of institutional delivery distribution in the country; furthermore, SaTscan statistics enabled us to identify specific local clusters, which are necessary for specific local interventions. According to Table 2 and Fig. 4, there were one primary/most likely and six secondary and significant clusters in the country. Totally 27 locations with Coordinates/radius - $(6.639662 \mathrm{~N}, 44.465853$ E) / $390.28 \mathrm{~km}$ ) with relative risk (RR) of 1.80 and LL of 187.82 were included in the primary cluster. The cluster was located in the Somali region including some borders of Oromia. It means these areas were $1.80(p<0.001)$ times more at risk of home delivery. The remaining clusters are secondary and presented in Table 2 and Fig. 4.

\section{Multilevel modeling of the institutional delivery}

During multilevel modeling: age, highest education level achieved, preceding birth interval, literacy status, wealth status, and birth order at the individual level and place of residence and region at community level were significant associated with institutional delivery.

\section{Individual-level}

Women in the age group of 20-24, 25-29, and $30-34$ years were $2.87,2.70$, and 2.92 times more likely to deliver in institutions with AOR of 2.87(1.02-8.10), $2.70(0.93-7.90)$, and $2.92(1.29-6.61)$ respectively. Women who learned primary, secondary and higher education had higher odds of delivering in institutions with AOR of 1.52(1.20-1.95), 1.77(1.03-3.07), and 5.41(1.91-15.25) respectively relative to those not educated. The odds of delivering in health institutions were also increased as the preceding birth interval increased with AOR of 1.01(1.01-1.02). Women who can read and write sentences had a higher tendency of delivering in health institutions with AOR of 1.94(1.28-2.94) unlike those who can't. Rich women had higher odds of delivering in health institutions with AOR of 2.40(1.82-3.16). Birth order of second had higher odds to happen in institutions than the first birth with AOR of 1.86(1.41-2.44). Moreover, women who followed $1-2,3$, and $\geq 4$ ANCs had higher odds of delivering in health institutions with AOR of 2.08(1.57-2.76), 3.24(2.51-418), and 4.91(3.93$6.15)$ respectively.

\section{Community-level}

Women in Tigray, Amhara, Benishangul, SNNP, Gambella, Harari, Addis Ababa, and Dire Dawa had higher odds of delivering in institutions compared to those in Afar with AOR of 9.35(3.83-22.90), 3.82(1.67-8.73), 13.00(5.89-28.69), $4.89(2.21-10.81), \quad 4.22(1.75-10.17)$, 3.67(1.60-8.42), 13.15(3.22-53.57), and 4.83(2.05-11.38) respectively, while women in those regions who live in a rural area had $78 \%$ reduced chance of delivering in health institutions with AOR of 0.18(0.11-0.31) (Table 3).

The application of multilevel binary logistic regression was proved vital by abridging the ICC (the variation observed only due to the differences among clusters) from 61 to $28 \%$. The remaining $28 \%$ unexplained intercommunity variation can be reduced by including 


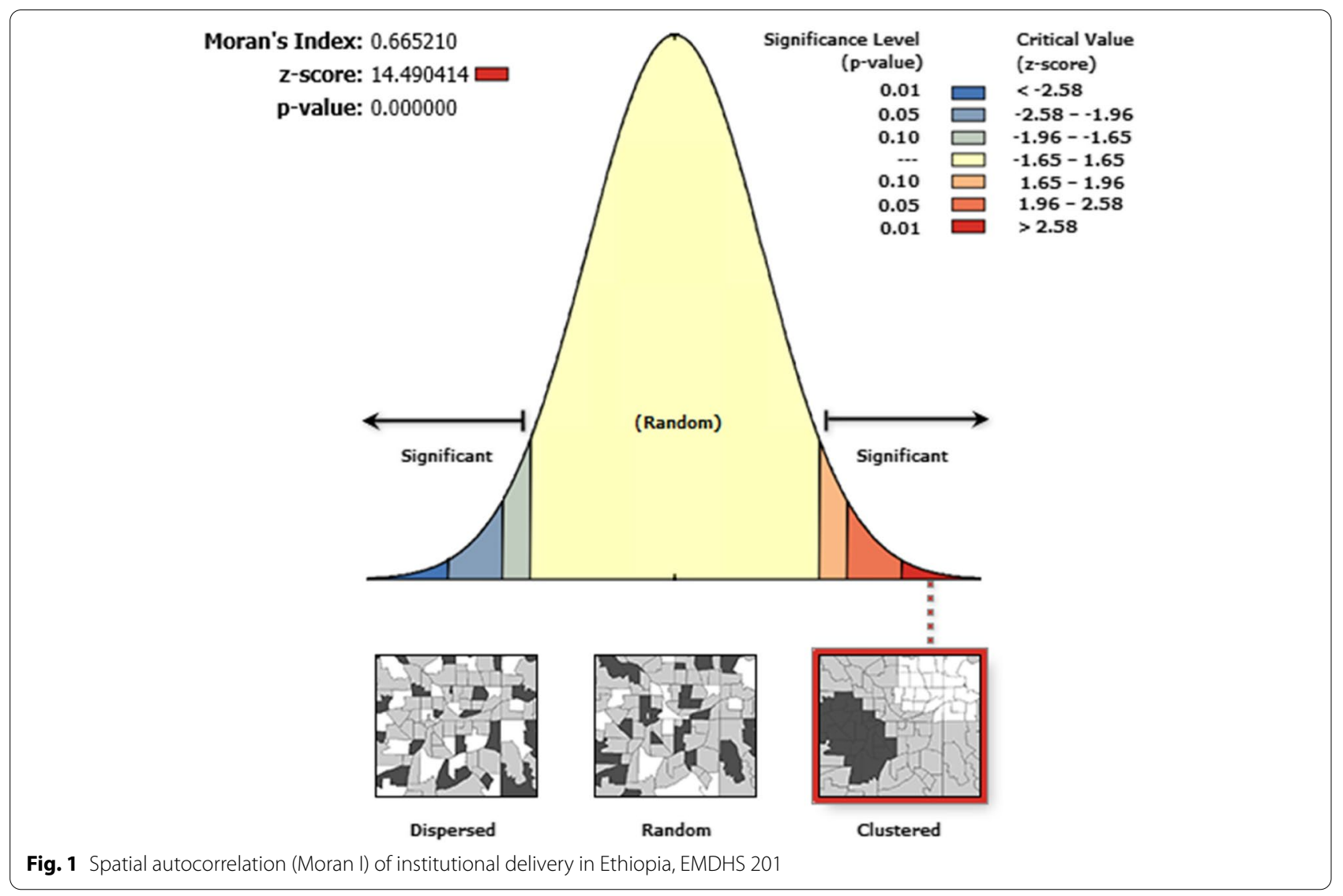

Spatial distribution of institutional delivery in Ethiopia, 2019
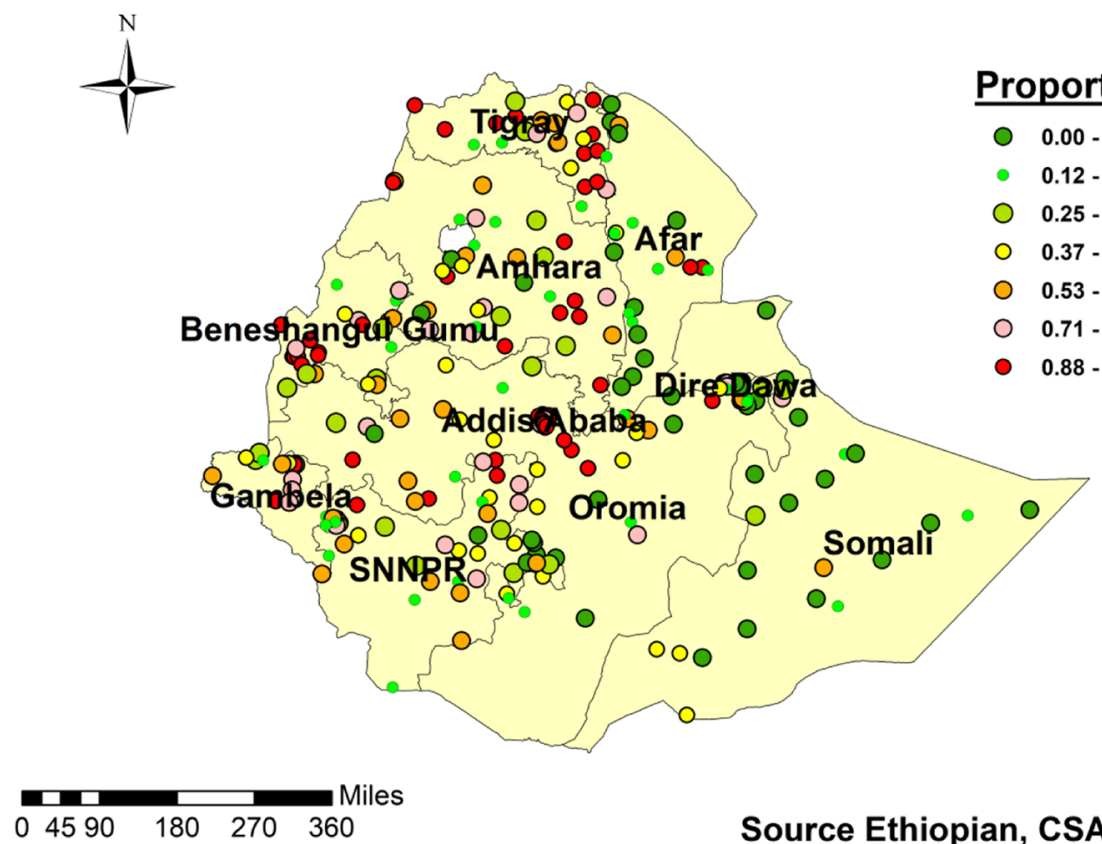

Source Ethiopian, CSA,2013

Fig. 2 Spatial distribution of institutional delivery in Ethiopian, EMDHS 2019 


\section{Interpolation analysis of institutional delivery in Ethiopia, 2019}

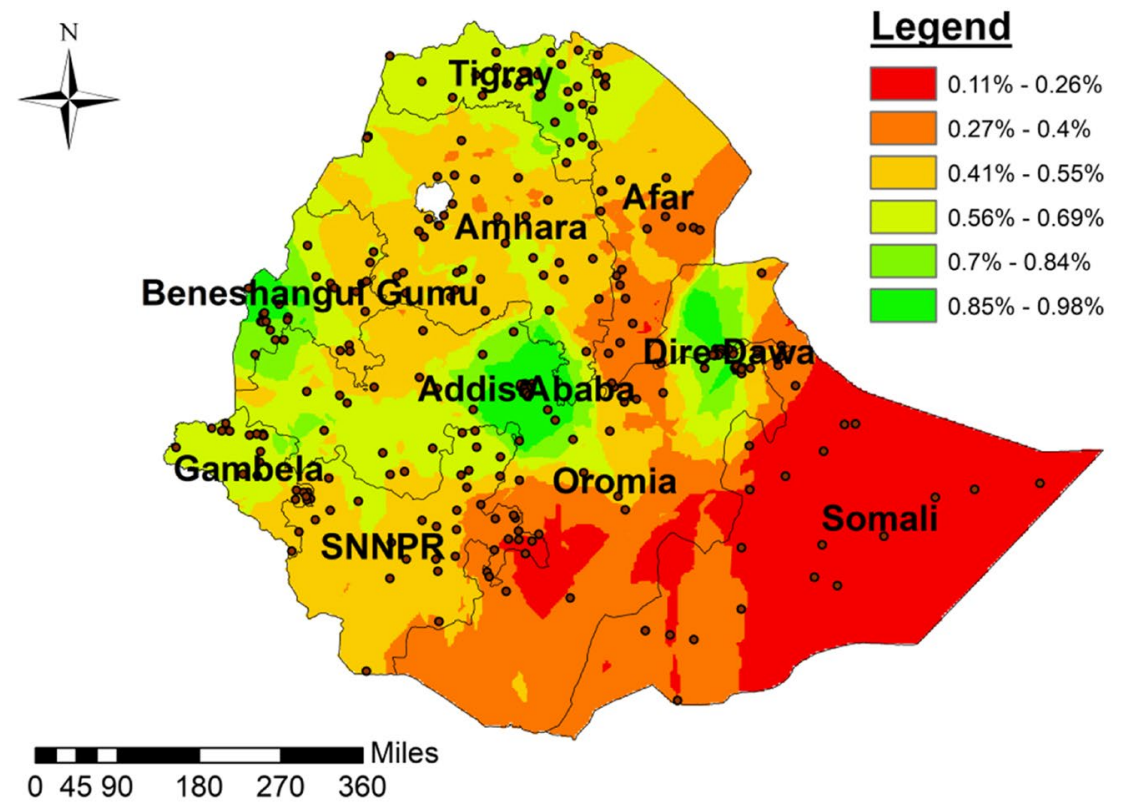

Source Ethiopian, CSA,2013

Fig. 3 Ordinary Kriging interpolation of institutional delivery in Ethiopia, EMDHS 2019

Table 2 Most likely clusters of institutional delivery among women of childbearing age in Ethiopia based on the EMDHS 2019

\begin{tabular}{lllllll}
\hline Clusters & Expected cases & Observed case & RR & LLR & p-value & Location regions \\
\hline 1 & 356.98 & 1.64 & 1.80 & 187.82 & $<0.001$ & Somali and Oromia \\
2 & 217.27 & 1.69 & 1.79 & 129.88 & $<0.001$ & Somali and Oromia \\
3 & 436.40 & 1.35 & 1.66 & 71.39 & $<0.001$ & parts of Afar, Oromia, and Amhara \\
4 & 174.64 & 1.52 & 1.57 & 55.50 & $<0.001$ & Eastern part of SNNP \\
5 & 30.31 & 1.91 & 1.93 & 34.56 & $<0.001$ & Afar and Tigray \\
6 & 116.08 & 1.48 & 1.51 & 30.37 & $<0.001$ & Afar, Amhara, and Tigray \\
7 & 36.98 & 1.78 & 1.80 & 27.94 & $<0.001$ & Somali and Afar \\
\hline
\end{tabular}

more other community-level factors in the model. The increased log-likelihood and decreased deviance were an indication of good model fitness (Table 4).

\section{Discussion}

\section{Institutional delivery}

Of the 5488 women involved in the current study, $48.58 \%$ were given births in health institutions. Evidence from other studies in the country unveiled institutional delivery was $71.7 \%$ in Dejen [33], 78.8\% in Bair Dar [22], $38 \%$ in Mandura district [20], and 38.9\% in 2016 EDHS [12]. There was a high variation from pocket studies but it showed good improvement from EDHS 2016. All the inconsistencies might be an indication of inconsistent interventions that need consideration during the next interventions (Table 1).

\section{Individual and community level characteristics}

Although there was no adequate evidence to support, the average number of children was $4.03 \pm 2.47$ in the current study. In Mizan Tapi SNNP, $40 \%$ of the women had 3 to 4 children [34]. It was 1 to 4,2 to 4 , and 4 to 6 children in other studies in the country [15, 34, 35]. There were many inconsistencies, but our study might show the representative national figure. In other words, 


\section{Spatial Satscan analysis of institutional delivery in Ethiopia 2019}

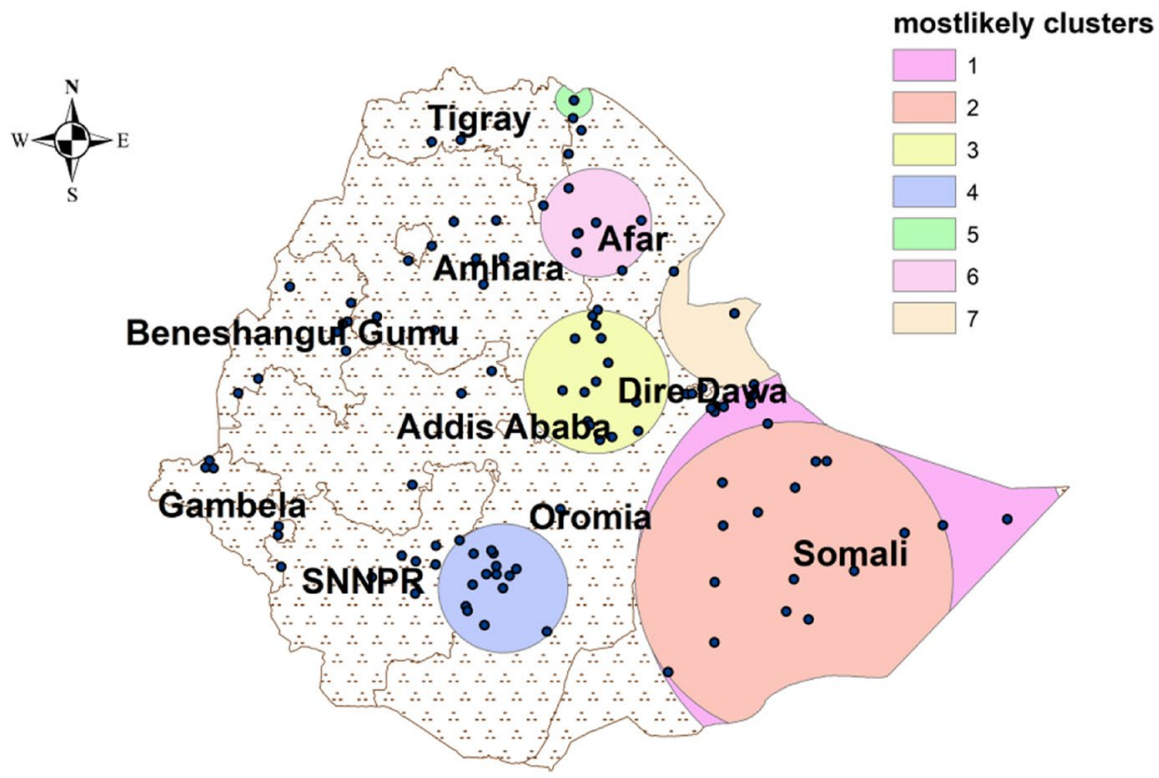

$0 \quad 50100 \quad 200 \quad 300 \quad 400$

Source: Ethiopian CSA,2013

Fig. 4 SaTScan scan statistics of institutional delivery in Ethiopia, EMHS 2019

the average birth interval was $40.61 \pm 26.30$ months. Evidence indicated that $43 \%$ of women in Ethiopia had an average preceding birth interval of $24-48$ months, and in East Africa, $82.1 \%$ had a preceding birth interval of $\geq 24$ moths [36]. In Ethiopia and even in the East of Africa, the average ranged between 24 and 48 months that is a good improvement over decades. However, the numbers of uneducated (53\%) and economically poor $(45.53 \%)$ women in this study were still very high. One study indicated that $79.2 \%$ of women in Ethiopia were uneducated [36] and resides in poor households $[12,13]$. The consistent finding might be an indication of unsuccessful previous efforts and need more considerations recently. In the same way, a large proportion of women had no ANC follow-up (47.45\%) and 64.34\% of them were unable to read and write. Evidence from other studies also showed that $54 \%$ of the women giving birth in Ethiopia were unable to read and write [37] and $56 \%$ of them followed no ANC [38]. Overall, women's literacy status and ANC follow-up have remained below par and invite more intervention. The fact that more than $75 \%$ of women residing in the rural parts of the country might also contribute to the above findings as indicated in similar studies $[15,37]$ (Table 1).

\section{Spatial distributions}

The attempt of localizing the findings to the specific regions for enhanced interventions was successful; the distribution of institutional delivery could guide interventions as it showed clustering in some parts of the country. The significant Moran's test of positive and greater than zero, the hot/cold spot areas identified with significant $\mathrm{z}$-score, the predictions made from known spatial location of event occurrence (spatial interpolation) of $\geq 0.56 \%$, and spatial scan statistics which encircled significant areas were enabled us to identify the regions needed more attention of improving institutional delivery in the country and were supported with other studies [14, 16]. From Table 2 and Figs. 1, 2, 3, and 4, we recognized the clustering nature of institutional delivery in Ethiopia. Accordingly, Addis Ababa, Hawassa, Dire Dawa, some parts of Benishangule Gumuz, and Oromia were found to be areas with a high proportion of institutional deliveries. However, Somali, Afar, some parts of SNNP, Oromia, and Amhara also showed low institutional delivery. This finding is also consistent with a systematic review done in the country [8], EDHS 2016 [4], spatial variation study in Northern Ethiopia, and EDHS 2005-2011 [38-40]. 
Table 3 Multilevel modeling of institutional delivery among women aged 15-49years in Ethiopia, 2019

\begin{tabular}{|c|c|c|c|c|}
\hline Variables & Model 0 & Model I & Model II & Model III \\
\hline Age & & & - & \\
\hline $15-19$ & - & 1 & - & 1 \\
\hline $20-24$ & - & $2.46(1.10-5.52)^{*}$ & - & $2.38(1.07-5.30)^{*}$ \\
\hline $25-29$ & - & $2.68(1.20-5.97)^{*}$ & - & $2.422(1.10-5.36)^{*}$ \\
\hline $30-34$ & - & $3.43(1.51-7.7 .9)^{* *}$ & - & $2.92(1.29-6.61)^{*}$ \\
\hline $35-39$ & - & $3.13(1.33-7.24)^{* *}$ & - & $2.60(1.12-6.02)$ \\
\hline $40-44$ & - & $3.08(1.26-7.54)^{*}$ & - & $2.50(1.30-6.10)$ \\
\hline $45-49$ & - & $2.32(0.85-6.27)$ & - & $1.70(0.62-4.52)$ \\
\hline Highest education level achieved & - & & - & \\
\hline No education & - & 1 & - & 1 \\
\hline Primary education & - & $1.60(1.25-2.06)^{* *}$ & - & $1.52(1.20-1.95)^{* *}$ \\
\hline Secondary education & - & $1.96(1.13-3.39)^{* *}$ & - & $1.77(1.03-3.07)^{* *}$ \\
\hline Higher education & - & $6.89(2.48-19.17)^{* *}$ & - & $5.41(1.91-15.25)^{* *}$ \\
\hline Preceding birth interval & - & $1.01(1.00-1.02)^{* * *}$ & - & $1.01(1.00-1.02)^{* * *}$ \\
\hline Literacy status & - & & - & \\
\hline Not read and write & - & 1 & - & 1 \\
\hline Able to read whole sentence & & $1.24(0.88-1.75)$ & & $1.15(0.81-1.62)$ \\
\hline Read and write sentence & & $2.19(1.44-3.35)^{*}$ & & $1.94(1.28-2.94)^{*}$ \\
\hline No card with the language & & $1.32(0.84-2.06)$ & & $1.51(0.94-2.40)$ \\
\hline ANC visits & - & & - & \\
\hline No ANC & - & 1 & - & 1 \\
\hline $1-2$ ANC & - & $2.09(1.57-2.77)^{* * *}$ & - & $2.08(1.57-2.76)^{* * *}$ \\
\hline 3 ANC & - & $3.27(2.57-4.23)^{* * *}$ & - & $3.24(2.51-418)^{* * *}$ \\
\hline$\geq 4$ ANCs & - & $5.19(4.15-6.48)^{* * *}$ & - & $4.91(3.93-6.15)^{* * *}$ \\
\hline Wealth status & - & & - & \\
\hline Poor & - & 1 & - & 1 \\
\hline Middle & - & $1.10(0.84-1.44)$ & - & $1.06(0.81-1.38)$ \\
\hline Rich & - & $3.48(2.66-4.56)^{* * *}$ & - & $2.40(1.82-3.16)^{* * *}$ \\
\hline Birth order & - & & - & \\
\hline First & & Empty & & Empty \\
\hline 2nd & & $1.80(1.444-2.47)^{* * *}$ & & $1.86(1.41-2.44)^{* * *}$ \\
\hline$>3$ & & Omitted & & Omitted \\
\hline Region & - & & & \\
\hline Tigray & - & & $19.14(7.70-47.56)^{* * *}$ & $9.35(3.83-22.90)^{* * *}$ \\
\hline Afar & - & & 1 & 1 \\
\hline Amhara & - & & $7.63(3.33-17.58)^{* * *}$ & $3.82(1.67-8.73)^{* * *}$ \\
\hline Oromia & - & & $4.11(1.81-9.30)^{* * *}$ & $2.39(1.14-5.01)$ \\
\hline Somali & - & & $0.53(0.21-1.31)$ & $0.93(0.44-2.09)$ \\
\hline Benishangul & - & & $18.29(7.42-45.06)^{* * *}$ & $13.00(5.89-28.69)^{* * *}$ \\
\hline SNNPR & - & & $5.17(2.29-11.70)^{* * *}$ & $4.89(2.21-10.81)^{* * *}$ \\
\hline Gambela & - & & $6.45(2.65-15.68)^{* * *}$ & $4.22(1.75-10.17)^{* * *}$ \\
\hline Harari & - & & 8.93.(3.45-23.10) & $3.67(1.60-8.42)^{* * *}$ \\
\hline Addis Ababa & - & & $16.20(5.15-50.98)^{* * *}$ & $13.15(3.22-53.57)^{* * *}$ \\
\hline Dire Dawa & - & & $8.83(3.34-23.35)^{* * *}$ & $4.83(2.05-11.38)^{* * *}$ \\
\hline Residence & - & & & \\
\hline Urban & - & & 1 & \\
\hline Rural & - & & $0.06(0.03-0.10)^{* * *}$ & $0.18(0.11-0.31)^{* * *}$ \\
\hline
\end{tabular}


Table 4 Model comparison and random effect distribution institutional delivery among reductive age women in Ethiopia in 2019

\begin{tabular}{lllll}
\hline Random effect model comparison & Model 0 & Model 1 & Model 2 & Model 3 \\
\hline Community-level Variance & 5.33 & 1.57 & 2.07 & 0.38 \\
Inter-cluster correlation (ICC) & 0.62 & 0.32 & -2743 & 0.28 \\
Log likelihood ratio (LLR) & -2861 & -1057 & 5486 & -1021 \\
Deviance & 5722 & 2114 & 0.48 & 2042 \\
Proportional change in variance (PCV) & Ref & 0.71 & & 0.75 \\
Media odds ratio (MOR) & 9.02 & &
\end{tabular}

\section{Multilevel analysis of predictors}

According to multilevel binary logistic regression analysis, women in the age group of 20-24, 25-29, and 30-34 years had higher odds of institutional delivery. Similar evidences were found in other studies in the country $[37,41]$. The consistent information might indicate institutional delivery increased at the time women might take more responsibilities for their births in the middle ages of the childbearing period. In other words, women's education and literacy were independent predictors of institutional delivery. This is a very global finding and common in most studies [35, 42, 43] and might indicate that improving mothers' educational and literacy status might be very vital to robust institutional delivery. Mothers who had any ANC visits showed a high correlation of delivering in institutions. The finding was also supported with plenty of evidence from similar studies $[26,35,42]$. The exposure of mothers to health professional counseling might be a factor that spurred the utilization; however, it might also be because of they were the only mothers who had access. Additionally, mothers with rich wealth status had a higher tendency of delivering in institutions as is also the case in other studies [36, 44]. This might show that in addition to access, availability, and affordability could be considered during interventions. In this study, mothers tend to give birth at health institutions for later pregnancies which were also common in other studies [45] (Table 3).

Contextual analysis indicated that except Oromia, all agrarian regions and city administrations showed good institutional deliveries; however, pastoralists regions (Somali and Afar) showed high home deliveries; henceforth, the home delivery was also higher in rural areas. Other studies also supported this finding $[4,16]$. During this analysis, we recognized many limitations. Among them, disproportionate sampling, using third party data, secondary nature of data, hierarchical nature of the data, lack of GPS coordinates for few records, and cross sectional nature of the study were some of the limitations. To handle disproportionate sampling, we applied weighting to the data before analysis. To deal with the third party nature of the data, we applied all the necessary protocols which are internationally standards to all countries and described all methods and manipulation of the data under method section. Due to the hierarchical nature of the data, we conducted multilevel binary logistic analysis. We also followed all standard methods to comprehend whether each captured data fit to the standard set by international DHS authorities. For the data without coordinates, we removed the records so that each event can be located on the test map.

\section{Conclusions}

After 2016 EDHS, EMDHS was the first country representative data to make an impression about distribution and factors associated with institutional deliveries in Ethiopia. According to our analysis, although there was good progress from some previous evidence, institutional delivery was still low and requires enhanced further interventions. Factors that contributed to low prevalence were age, highest education level achieved, preceding birth interval, literacy status, wealth status, birth order, regions, and rural residences. The positive correlation of institutional delivery with educational/literacy status and ANC might invite further interventions in the area of awareness, access, and availability of the service. Regional disparities need specific interventions as pastoralist regions showed poor institutional delivery, while economic support for women in the rural area needs to be in the equation as the part of the further policy interventions.

\section{Abbreviations \\ WHO: World Health Organization; EDHS: Demographic Health Survey; EMDHS: Ethiopian Demographic Health survey; ANC: Antenatal Care; AOR: Adjusted Odds Ratio; Cl: Confidence Interval; SNNPR /SNNP: South Nations Nationali- ties people Region; EHNRI: Ethiopian Health Nutrition and Research Institute; NRERC: Review Board and the National Research Ethics Review Committee; ICC: Intra-Cluster Correlation; LL: Log likelihood; RR: Relative Risk; MOR: Median Odds Ratio; PCV: Proportional Change in Variance; MDG: Millennium Develop- ment Goals; PWMHC: Participation of Women in Monthly Health Conference; CSA: Central Statistics Agency; P: P-value; GPS: Global Positioning System.}

\section{Acknowledgments}

We are very grateful to EMDHS program for the permitting us to access the data and our gratitude should also goes to the other stakeholders who involved directly or indirectly. 


\section{Authors' contributions}

GG developed the proposal, writing results, drafting the manuscript, SH was involved in the conception, analysis, and revising of the final manuscript and BTS was also involved writing results, analysis and drafting manuscript. The author(s) read and approved the final manuscript.

\section{Funding}

We received no funds for this work.

\section{Availability of data and materials}

The data used in this study are the third-party data available from the Demographic and Health Survey (http://www.dhsprogram.com) and can be easily accessed by following the protocol indicated in the methods and materials section.

\section{Declarations}

Ethics approval and consent to participate

We kept information regarding respondents confidential. We exposed household or individual identifying information neither during analysis nor during the publication. For EMDHS data collection, the Ethiopian Health Nutrition and Research Institute (EHNRI) Review Board and the National Research Ethics Review Committee (NRERC) at the Ministry of Science and Technology were provided permission. After clearing the purpose of the study, verbal informed consent was collected from the participants and all participants' rights were respected.

\section{Consent for publication}

Not applicable.

\section{Competing interests}

The authors declare that they have no competing interests.

\section{Author details}

'Department of Health Informatics, School of Public Health, College of Medicine and Health Sciences, Arba Minch University, Arba Minch, Ethiopia.

${ }^{2}$ Department of Health Informatics, School of Public Health, College of Medicine and Health Sciences, Dilla University, Dilla, Ethiopia.

Received: 2 Auqust 2021 Accepted: 4 February 2022

Published online: 21 February 2022

\section{References}

1. Gebremichael SG, Fenta SM. Determinants of institutional delivery in sub-Saharan Africa: findings from demographic and health survey (2013-2017) from nine countries. Trop Med Health. 2021;49:45. https:// doi.org/10.1186/s41182-021-00335-x.

2. Federal Democratic Republic of Ethiopia Ministry of Health. Ethiopian Health Sector Transformation Plan.2015/16-2019/20. Fed Democr Repub Ethiop Minist Heal. 2015;20(May):50 Available from: https:// www.globalfinancingfacility.org/sites/gff_new/files/Ethiopia-healthsystem-transformation-plan.pdf.

3. Abebe F, Berhane Y, Girma B. Factors associated with home delivery in Bahirdar, Ethiopia: a case control study. BMC Res Notes. 2012;5:653. https://doi.org/10.1186/1756-0500-5-653.

4. Muluneh AG, Animut $Y$, Ayele TA. Spatial clustering and determinants of home birth after at least one antenatal care visit in Ethiopia: Ethiopian demographic and health survey 2016 perspective. BMC Pregnancy Childbirth. 2020;20(1):1-13.

5. Chernet AG, Dumga KT, Cherie KT. Home delivery practices and associated factors in Ethiopia. J Reprod Infertil. 2019;20(2):102-8.

6. Delibo D, Damena M, Gobena T, Balcha B. Status of home delivery and its associated factors among women who gave birth within the last 12 months in east Badawacho District, Hadiya zone, southern Ethiopia. Biomed Res Int. 2020;2020:4916421.

7. Ayele G. Prevalence and associated factors of home delivery in Arbaminch Zuria District, southern Ethiopia: community based cross sectional study. Sci J Public Heal. 2015:3(1):6.
8. Ayenew AA, Nigussie A, Zewdu B. Prevalence of home delivery and associated factors in Ethiopia: A systematic review and meta-analysis; 2020. p. $1-27$.

9. Evans DB, Hsu J, Boerma T. Universal health coverage and universal access. Bulletin of the World Health Organization. 2013;91:546-A.

10. Gedilu T, Debalkie D, Setegn T. Prevalence and determinants of institutional delivery service uptake among women in Farta District, Northwest Ethiopia. J Nurs Care. 2018;07(02):2167-1168.

11. Yoseph M, Abebe SM, Mekonnen FA, Sisay M, Gonete KA. Institutional delivery services utilization and its determinant factors among women who gave birth in the past 24 months in Southwest Ethiopia. BMC Health Serv Res. 2020;20(1):1-0.

12. Berelie $Y$, Yeshiwas D, Yismaw L, Alene M. Determinants of institutional delivery service utilization in Ethiopia: a population based cross sectional study. BMC Public Health. 2020;20(1):1-10.

13. Ketemaw A, Tareke M, Dellie E, Sitotaw G, Deressa Y, Tadesse G, et al. Factors associated with institutional delivery in Ethiopia: a cross sectional study. BMC Health Serv Res. 2020;20(1):1-6.

14. Yeneneh A, Alemu K, Dadi AF, Alamirrew A. Spatial distribution of antenatal care utilization and associated factors in Ethiopia: evidence from Ethiopian demographic health surveys. BMC Pregnancy Childbirth. 2018:18(1):1-12.

15. Alemayehu M, Mekonnen W. The prevalence of skilled birth attendant utilization and its correlates in north West Ethiopia. Biomed Res Int. 2015:2015:436938.

16. Tesema GA, Mekonnen TH, Teshale AB. Individual and communitylevel determinants, and spatial distribution of institutional delivery in Ethiopia, 2016: Spatial and multilevel analysis. PLoS One. 2020;15((11 November)):e0242242. Available from:. https://doi.org/10.1371/journal. pone.0242242.

17. Fikre AA, Demissie M. Prevalence of institutional delivery and associated factors in Dodota Woreda (district), Oromia regional state, Ethiopia. Reprod Health. 2012;9(1):1-24.

18. Wayessa ZJ, Dukale UG. Factors associated with institutional delivery among women in Bule Hora town, Southern Ethiopia. Midwifery. 2021:97(March 2018):3-5.

19. Belay AS, Sendo EG. Factors determining choice of delivery place among women of child bearing age in Dega Damot District, north west of Ethiopia: a community based cross- sectional study. BMC Pregnancy Childbirth. 2016:16(1):1-8. Available from:. https://doi.org/10.1186/ s12884-016-1020-y.

20. Anteneh KT, Gebreslasie KZ, Nigusie TS, Aynalem GL, Yirdaw BW. Utilization pattern of institutional delivery among mothers in North-western Ethiopia and the factors associated; A community - based study. Clin Epidemiol Glob Heal. 2021;10(December 2020):100675. Available from: https://doi.org/10.1016/j.cegh.2020.100675.

21. Yosef T. Magnitude and associated factors of institutional delivery among reproductive age women in Southwest Ethiopia. Int J Women's Health. 2020;12:1005-11.

22. Gedefaw A, Muluken A, Tesfaye S. Factors associated with institutional delivery service utilization among mothers in Bahir Dar City administration, Amhara region: A community based cross sectional study. Reprod Health. 2014;11(1):22.

23. Rosado C, Callaghan-Koru JA, Estifanos A, Sheferaw E, Shay T, De Graft-Johnson J, et al. Effect of birth preparedness on institutional delivery in Semiurban Ethiopia: a cross-sectional study. Ann Glob Heal. 2019:85(1):1-11.

24. Mitikie KA, Wassie GT, Beyene MB. Institutional delivery services utilization and associated factors among mothers who gave birth in the last year in Mandura district, Northwest Ethiopia. PLoS One. 2020;15(12 December):1-17. Available from:. https://doi.org/10.1371/journal.pone.0243466.

25. Anshebo D, Geda B, Mecha A, Liru A, Ahmed R. Utilization of institutional delivery and associated factors among mothers in Hosanna Town, Hadiya Zone, Southern Ethiopia: A community-based cross-sectional study. PLoS One. 2020;15(12 December):1-12. Available from:. https://doi.org/10. 1371/journal.pone.0243350.

26. Assefa M, Fite RO, Taye A, Belachew T. Institutional delivery service use and associated factors among women who delivered during the last 2 years in Dallocha town, SNNPR, Ethiopia. Nurs Open. 2020;7(1):186-94. 
27. Temesgen H, Worku A, Fekadu Demissie H, Tafa Segni M, Adugna S, Amdemichael $\mathrm{R}$, et al. Institutional delivery services utilization and associated factors at Hetosa District, Ethiopia. Am J Life Sci. 2020;8(4):60.

28. Yesuf EA, Kerie MW, Calderon-Margalit R. Birth in a health facility -inequalities among the Ethiopian women: results from repeated national surveys. PLoS One. 2014;9(4):1-8.

29. United Nations. Millennium development goals report., New York; 2008. p. 24-5. Available from: https://www.un.org/millenniumgoals/2015_ MDG_Report/pdf/MDG\%202015\%20rev\%20(July\%201).pdf

30. Ethiopian Public Health Institute (EPHI) [Ethiopia] and ICF. Ethiopia Mini demographic and health survey 2019: final report. Rockville: EPHI and ICF; 2021. Vailable from: https://dhsprogram.com/pubs/pdf/FR363/FR363.pdf

31. Mboane R, Bhatta MP. Influence of a husband's healthcare decision making role on a woman's intention to use contraceptives among Mozambican women. Reprod Health. 2015;12:36.

32. Belachew AB, Kahsay AB, Abebe YG. Individual and community-level factors associated with introduction of prelacteal feeding in Ethiopia. Arch Public Heal. 2016;74(1):1-11. Available from:. https://doi.org/10.1186/ s13690-016-0117-0.

33. Desta M. Determinants of institutional delivery among mothers who gave birth in the last one year in Dejen Woreda, Ethiopia, 2016: a cross sectional study. J Fam Med Heal Care. 2017;3(3):45.

34. Masino TT. Prevalence of institutional delivery among mothers in Kometa sub-locality, Mizan-Aman town, Southwest Ethiopia ICUS. Nurs Web J. 2016;10(1):1-6

35. Wolelie A, Aychiluhm M, Awoke W. Institutional delivery service utilization and associated factors in Banja District, Awie zone, Amhara regional sate, Ethiopia. Open J Epidemiol. 2014;04(01):30-5.

36. Tesema GA, Tessema ZT. Pooled prevalence and associated factors of health facility delivery in East Africa: Mixedeffect logistic regression analysis. PLoS One. 2021;16(4 April):1-16. Available from:. https://doi.org/ 10.1371/journal.pone.0250447.

37. Muluwas Amentie $B$, Abdulahi $M$, Amentie a M, $\sigma \mathrm{M}$, Abdulahi $\rho \mathrm{M}$. Utilization of institutional delivery care services and influencing factors among women of child bearing age in Assosa District, Benishangul Gumuz regional state, West Ethiopia. Glob J Med Res E Gynecol Obstet. 2016;16(3):35-44.

38. Teferra AS, Alemu FM, Woldeyohannes SM. Institutional delivery service utilization and associated factors among mothers who gave birth in the last 12 months in Sekela District, north west of Ethiopia: a community based cross sectional study. BMC Pregnanfile///F/New folder/institutional Deliv Childbirth. 2012:12:74

39. Nigusie A, Azale T, Yitayal M. Institutional delivery service utilization and associated factors in Ethiopia: a systematic review and META-analysis. BMC Pregnancy Childbirth. 2020;20(1):1-25.

40. Tessema ZT, Tiruneh SA. Spatio-temporal distribution and associated factors of home delivery in Ethiopia. Further multilevel and spatial analysis of Ethiopian demographic and health surveys 2005-2016. BMC Pregnancy Childbirth. 2020;20(1):1-16.

41. Nigatu AM, Gelaye KA, Degefie DT, Birhanu AY. Spatial variations of women's home delivery after antenatal care visits at lay Gayint District, Northwest Ethiopia. BMC Public Health. 2019;19(1):1-14.

42. Kebede A, Hassen $\mathrm{K}$, Teklehaymanot AN. Factors associated with institutional delivery service utilization in Ethiopia. Int J Women's Health. 2016:8:463-75.

43. Bekele D. Point prevalence and factors associated with institutional delivery among married women in reproductive age in Abe Dongoro Woreda, Horro Guduru Wollega Zone, Oromia Region, Western Ethiopia. 2016;13(10):28-41.

44. Demilew YM, Gebregergs GB, Negusie AA. Factors associated with institutional delivery in Dangila district, north West Ethiopia: a cross-sectional study. Afr Health Sci. 2016;16(1):10-7.

45. Antehunegn G, Worku MG. Individual-and community-level determinants of neonatal mortality in the emerging regions of Ethiopia: a multilevel mixed-effect analysis. BMC Pregnancy Childbirth. 2021;21(1):1-11.

\section{Publisher's Note}

Springer Nature remains neutral with regard to jurisdictional claims in published maps and institutional affiliations.

Ready to submit your research? Choose BMC and benefit from:

- fast, convenient online submission

- thorough peer review by experienced researchers in your field

- rapid publication on acceptance

- support for research data, including large and complex data types

- gold Open Access which fosters wider collaboration and increased citations

- maximum visibility for your research: over $100 \mathrm{M}$ website views per year

At BMC, research is always in progress.

Learn more biomedcentral.com/submissions 